\title{
Chemotherapy appointment scheduling under uncertainty by considering workload balance among nurses
}

\author{
Kemoterapi randevularının hemşireler arasındaki iş yükü dengesi \\ gözetilerek belirsizlik altında çizelgelenmesi
}

\author{
Serhat GUL $1^{*}$ iD \\ 1Department of Industrial Engineering, Faculty of Engineering, TED University, Ankara, Turkey. \\ serhat.gul@tedu.edu.tr
}

\begin{abstract}
Balancing nurse workload while scheduling outpatient chemotherapy appointments under uncertainty is a challenging problem. In this study, a two-stage stochastic mixed-integer programming model is proposed for setting appointment times of patients and assigning patients to chairs and nurses without distorting the workload balance among nurses. The uncertainty in pre-medication and infusion durations is considered. The objective function of the model minimizes the expected weighted sum of patient waiting time and nurse overtime. Computational experiments are conducted based on data from an outpatient chemotherapy unit of a large hospital. The trade-off between the two competing criteria of the study is investigated. The relationship between the numbers of chairs and nurses in the clinic with the performance measures is examined. The benefit of considering uncertainty is assessed by calculating the value of stochastic solution
\end{abstract}

Keywords: Chemotherapy scheduling, Stochastic programming, Healthcare operations.

\begin{abstract}
Öz
Belirsizlik varken ayaktan kemoterapi randevularının çizelgelenmesi esnasında hemșirelerin iș yükünü dengelemek zor bir problemdir. $\mathrm{Bu}$ çalışmada, hastaların randevu vakitlerinin belirlenmesini ve hemșirelerin kendi aralarındaki iș yükü dengesini bozmadan hastaların koltuklara ve hemşirelere atanmasını sağlayan iki aşamalı stokastik karışık tamsayılı programlama modeli tasarlanmıştır. Çalışmada premedikasyon ve infüzyon sürelerindeki belirsizlik dikkate alınmıștır Modelin amaç fonksiyonu, hastaların bekleme süreleri ve hemșirelerin fazla mesai sürelerinin ağırlıklandırılmıș toplamının beklenen değerini enküçüklemektedir. Büyük bir hastanenin ayaktan kemoterapi ünitesinden elde edilmiş veriler kullanılarak bilgisayısal deneyler yapılmıştır. Çalışmada gözetilen iki rakip ölçüt arasındaki denge incelenmiștir. Klinikte bulunan koltuk ve hemșire sayıs ile performans ölçütleri arasındaki ilișki irdelenmiștir. Stokastik çözüm değeri hesaplanarak, belirsizliği dikkate alarak çözüm bulmanın faydas ölçülmüstür.
\end{abstract}

Anahtar kelimeler: Kemoterapi çizelgeleme, Stokastik programlama, Sağlık hizmeti operasyonları.

First, patients are allocated to days; next, the patient appointment times are set for each daily schedule. One or two days before the schedule is implemented, the schedules are finalized by fine-tuning the patient appointment times without making substantial changes [2]. We focus on the fine-tuning phase and reset the appointment times of a given schedule without making a change in the patient sequence.

Nurse overtime and patient waiting time are two important criteria for chemotherapy clinic managers. Nurse overtime negatively affects operating costs of the clinic. An excessive amount of overtime also reduces the workplace satisfaction level of nurses. Patient waiting time is a relevant measure representing service and patient satisfaction levels. Designing appointment schedules based on treatment duration estimates may lead to unacceptable amount of overtime and waiting time, especially at the clinics where the variability in durations is high.

The uncertainty in treatment durations must be given particular emphasis while scheduling appointments. The treatment duration may deviate from the expected value due to one of the following reasons: (i) need for early termination after the patient's resistance against given drugs, (ii) an increase in the effort spent after observing complications, (iii)

${ }^{*}$ Corresponding author/Yazışılan Yazar 
revision in the medication list [2]. In case a manager allocates more than expected duration to the cases, this may result in low amount of waiting times. On the other hand, this may cause an increase in nurse overtime. As expected, allocating less than needed amount of time may lead to large amount of waiting times and low amount of nurse overtime. The trade-off between these two measures must be carefully addressed by the decision maker.

It is important to maintain workload balance while allocating tasks among employees to improve personnel satisfaction in any service system. This issue needs particular attention in healthcare systems, because the medical conditions of patients may be negatively influenced if the care is provided by overloaded caregivers. Consideration of the limited availability of chairs and nurses in the clinic is also necessary while scheduling appointments. Nurses and chairs are simultaneously utilized by patients throughout the treatment. Furthermore, a nurse cannot perform more than one premedication at a given time. On the other hand, she can proctor multiple patients at any time during the infusion phase.

In this article, we study the problem of setting appointment times for a chemotherapy clinic while considering the nurse workload balance and limited availability of nurses and chairs under uncertainty related to pre-medication and infusion durations. We assume that a first draft of a schedule is already created, and appointment times are reset by preserving the original sequence of patients. The following decisions are given: (1) appointment time-setting; (2) patient-to-nurse assignment; and (3) patient-to-chair assignment. We model our problem as a two-stage stochastic mixed-integer programming (2SMIP) formulation. The objective function minimizes the expected weighted sum of patient waiting time and nurse overtime, where the expectation is taken over a large set of scenarios generated by sampling from distributions of pre-medication and infusion durations. We enhance the model by adding a symmetry-breaking constraint into the constraint set. We generate instances using data of a major oncology hospital, and conduct numerical experiments to investigate the optimal solutions. We evaluate the sensitivity of the performance measures to the changes in the weights for patient waiting time and nurse overtime. We analyze the impact of the variation in the number of chairs and nurses on the optimal schedules. We also assess the benefit of considering uncertainty in premedication and infusion durations during the task of scheduling chemotherapy appointments while considering nurse workload balance.

In the following section, literature review of chemotherapy scheduling studies is presented. In Section 3, the problem description is given first. Next, the 2SMIP model formulation and a model enhancement idea are discussed. In Section 4, a detailed computational study is provided. Finally, concluding remarks are presented in Section 5.

\section{Literature review}

We present a brief literature review of studies on outpatient chemotherapy scheduling problems. A detailed review of the subject can be found in Lame et al. [3]. Besides, the reader is referred to Gupta and Denton [4], Cayirli and Veral [5], and Ahmadi-Javid et al. [6] for an extensive review of articles on general outpatient clinics.

We first present the articles that ignore uncertainty in activity durations. Turkcan et al. [7] studied both planning and scheduling problems by formulating an integer programming (IP) model. They assigned patients to days in the first step, and then to the chairs, nurses and time slots in the second step. They minimized treatment delays and overtime in their models. Heshmat et al. [8] first grouped patients using clustering algorithms. Then, they assigned a nurse to each group of patients and chairs, and determined treatment start times based on an IP model. Sevinc et al. [9] also considered a twophase approach. They assumed that laboratory tests are conducted a day before the infusion. They first used a heuristic to determine the number of patients scheduled for lab tests with the objective of controlling daily load. They then assigned the patients who are approved to receive treatment to chairs again using a heuristic. Hesaraki et al. [10] determined the time slots for setup of patient treatments using a binary IP formulation having the objective of minimizing the makespan and weighted flow time. They considered nurse capacity constraints and patient priorities in their study as well. Liang and Turkcan [11] developed two separate mixed-integer programming models to assign patients to nurses and time slots, where each model considers a particular type of nurse care delivery. These are called as functional and primary care delivery models, respectively. Continuity is given priority in the primary care delivery, as the same nurse is assigned to a patient at each of her chemotherapy clinic visits. On the other hand, flexibility and efficiency is more important in functional care delivery, as any one of the nurses can be assigned to a patient at each of her visits. The authors considered skill levels of nurses and acuity levels of patients while making patient-tonurse assignments.

Our study is different from the above articles in the sense that we take uncertainty into account in our 2SMIP model. Other similar deterministic chemotherapy appointment scheduling models can be found in Santibanez et al. [12], Hahn-Goldberg et al. [13], and Huggins et al. [14]. We now review studies that consider stochastic factors relevant to chemotherapy clinics.

Alvarado and Ntaimo [15] proposed mean-risk stochastic integer programming models that can be used for only one patient to set slot, nurse and chair assignment decisions. They considered uncertainty related to the patient acuity levels, treatment durations, and number of nurses available on a day. The models can be used to improve total throughput, patient waiting time and nurse overtime. Note that we formulate a model that can be used to schedule multiple patients at the same time. Furthermore, we do not use time slots in our formulation to model uncertainty in treatment durations realistically.

Mandelbaum et al. [16] proposed a data-driven appointment scheduling approach by considering only the chairs as resources. The stochastic parameters in their study include treatment durations and punctuality of patients. Note that the study ignores nurse assignment decisions in contrast to our study.

Castaing et al. [2] solved a simpler version of our problem. They also refined the existing chemotherapy schedules by resetting the appointment times using a 2SMIP formulation. However, their model was formulated by considering a single nurse in a clinic. On the other hand, our model makes patient-to-nurse assignment decisions. Furthermore, we maintain nurse workload balance and examine the impact of its consideration into the performance measures. Since there are a number of nurse alternatives for a patient, our model is appropriate for 
clinics that work according to a functional care delivery model. However, as the nurse of a patient is fixed in Castaing et al. [2], their model was formulated only for the clinics that function based on primary care delivery model.

Demir et al. [17] also studied a stochastic chemotherapy appointment scheduling problem based on a 2SMIP model. However, they did not balance nurse workload while assigning patients to nurses. Furthermore, they considered patient-tochair and patient-to-nurse assignment decisions in the second stage of their formulation. On the other hand, these decisions are given under uncertainty at the first stage of our 2SMIP model. To ensure that nurses are aware that the work is fairly allocated among them, the work plan must be announced by the head nurse at the beginning of the day. This implies that the patient-to-nurse assignment decisions must be made before all patients arrive to the clinic. This enforces us to model these decisions at the first stage of our 2SMIP model. Hence, the structure of our stochastic programming model becomes different from that of Demir et al. [17]. They have binary and general integer variables at the first stage, and binary and continuous variables at the second stage. Our model includes only binary variables in the first stage and only continuous variables in the second stage. The resulting structure of our model allows us to solve the 2SMIP model without using a sophisticated approach such as the linearized progressive hedging algorithm (LPHA) proposed in Demir et al. [17]. The LPHA provides heuristic solutions due to the complexity induced by the binary variables in the second stage of their formulation. However, our model structure has the advantage of providing optimal solutions within a reasonable amount of time.

\section{Problem description}

We first provide background information on the chemotherapy clinic based on which we defined our problem. We then explain our model and an enhancement idea on the model representation.

\subsection{Background information}

We formulate our problem based on the patient flow in the chemotherapy clinic at the Hacettepe University Oncology Hospital in Ankara. Before we proceed with the definition of the problem, we describe the general characteristics of this clinic.

There are 28 chairs in the clinic that are directly used for chemotherapy treatment. The clinic serves 60 to 85 patients, on average, at a particular day. The patients are served by 9 nurses and a head nurse. The head nurse is responsible for determining the patient appointment times, and the assignment of patients to nurses and chairs each day. The clinic provides service in two shifts every day. The morning shift includes the period between 8:00 and 12:00, and the afternoon shift covers the period between 13:00 and 17:00. The time spent after the shift finish time is considered as overtime.

Blood test must be conducted before an approval is given for the treatment of a patient. The test result evaluation and treatment approval decision are made by an oncologist. The drug preparation order is sent to the pharmacy after the oncologist evaluation. Note that these phases are completed one day ahead of the treatment. We focus on the process flow on the day the patient arrives to the clinic for treatment. In particular, we consider two activities: (i) setup activity, through which the patient is prepared for the treatment and given pre- medication drugs to prevent side effects; and (ii) infusion phase, at which the patient receives actual drugs for treatment.

We now describe the patient flow on the day of treatment. First, the arriving patient at her appointment time is registered at the front desk and considered as available for treatment. The patient is taken to the infusion chair in case both a nurse and a chair are available. In case any of them is not idle, the patient needs to wait in the waiting area. A nurse checks her blood pressure and fever when the patient is taken to the chair. She also initiates the pre-medication process by opening a vascular access. Next, the infusion process follows pre-medication. Even though it is rare, some patients skip the pre-medication activity and only go through infusion. The patient gets discharged when the infusion is completed.

Since a nurse needs to monitor patients during the infusion process, each nurse is assigned at most four patients in general. The chemotherapy clinic at Hacettepe operates according to a modified version of the functional care delivery model. Therefore, the nurse treating a patient may differ from one visit to another. However, the type of patient is taken into account to maintain fairness while the workload is allocated among nurses.

In this article, we assume that the daily patient schedule for a chemotherapy outpatient unit is already created. We study how the existing schedule can be refined by resetting the patient appointment times and revising the nurse and chair assignments under uncertainty while also maintaining the nurse workload balance. We do not change the patient sequence while resetting the appointment times. We only aim to fine-tune the existing schedule since making significant amount of changes would require the permission of patients.

\subsection{Model description}

We formulate the problem as two-stage stochastic mixedinteger programming (2SMIP) model, inspired by the operations at the Hacettepe Chemotherapy Unit. The following decisions are made at the first stage, respectively: (1) appointment times are set for each patient; (2) each patient is assigned to a nurse; (3) each patient is assigned to a chair. Then, pre-medication and infusion durations are realized. At the second stage, patient waiting time and overtime values are determined.

The expected weighted sum of patient waiting time and nurse overtime are considered as the performance measures. Patients may wait due to the following reasons: (1) A chair may not be available; (2) the nurse responsible for the treatment may not be available. Nurse overtime is the additional amount of time that a nurse works after the regular closure time of the chemotherapy unit.

Assuming a finite set of scenarios that represent uncertainty in pre-medication and infusion times, we formulate the 2SMIP model as follows:

\subsubsection{Indices}

$\begin{array}{cll}\mathrm{i}, \mathrm{j} & : & \text { Patient index, } \\ \mathrm{k} & : & \text { Patient class index, } \\ \mathrm{n} & : & \text { Nurse index, } \\ \mathrm{c} & : & \text { Chair index, } \\ \mathrm{\omega} & : & \text { Scenario index. }\end{array}$

\subsubsection{Sets}

S : Set of all patients, 
$\mathrm{SP}_{\mathrm{j}} \quad$ : Set of patients that precede patient $\mathrm{j}$ in the appointment list,

$\mathrm{S}_{\mathrm{k}} \quad$ : Set of patients of class $\mathrm{k}$,

$\mathrm{N}$ : Set of all nurses,

C : Set of all chairs,

K : Set of all patient classes,

$\Omega \quad$ : Set of scenarios.

\subsubsection{Deterministic parameters}

$\mathrm{H}$ : Regular closure time for the infusion center,

L : : Upper limit on nurse overtime,

$\mathrm{P}_{\mathrm{k}} \quad$ : Upper limit on the number of patients of class $\mathrm{k}$ that can be assigned to a nurse,

$\lambda$ : Weight for waiting time $(\lambda \leq 1$ and $(1-\lambda)$ represents weight for overtime),

M : Large value.

\subsubsection{Random parameters}

$s_{i}(\omega)$ : Pre-medication duration for patient $\mathrm{i}$ under scenario $\omega$

$t_{i}(\omega) \quad$ : Infusion duration for patient i under scenario $\omega$.

\subsubsection{First-stage decision variables}

$\mathrm{a}_{\mathrm{i}} \quad$ : Appointment time for patient $\mathrm{i}$,

$\mathrm{x}_{\text {in }} \quad$ : Binary variable denoting whether patient $\mathrm{i}$ is assigned to nurse $\mathrm{n}$ or not,

$\mathrm{y}_{\mathrm{ic}} \quad$ Binary variable denoting whether patient $\mathrm{i}$ is assigned to chair $\mathrm{c}$ or not.

\subsubsection{Second-stage decision variables}

$\mathrm{w}_{\mathrm{i}}(\omega)$ : Waiting time of patient $\mathrm{i}$ under scenario $\omega$,

$o_{n}(\omega)$ : Overtime for nurse $n$ under scenario $\omega$.

\subsubsection{Objective function}

$$
\min \mathcal{Q}(\boldsymbol{x}, \boldsymbol{y}, \boldsymbol{a})=E_{\xi}[Q(\boldsymbol{x}, \boldsymbol{y}, \boldsymbol{a}, \xi(\omega)]
$$

\subsubsection{First-stage constraints}

$$
\begin{gathered}
\sum_{n \in N} x_{i n}=1 \quad \forall i \in S \\
\sum_{c \in C} y_{i c}=1 \quad \forall i \in S \\
\sum_{i \in S_{k}} x_{i n} \leq P_{k} \quad \forall n \in N, k \in K \\
x_{i n}, y_{i c} \in\{0,1\} \quad \forall i \in S, n \in N, c \in C \\
a_{i} \geq 0 \quad \forall i \in S
\end{gathered}
$$

\subsubsection{Second-stage recourse function}

$$
\begin{gathered}
Q(\boldsymbol{x}, \boldsymbol{y}, \boldsymbol{a}, \xi(\omega))= \\
\min \lambda \sum_{i \in S} w_{i}(\omega)+(1-\lambda) \sum_{n \in N} o_{n}(\omega)
\end{gathered}
$$

\subsubsection{Second-stage constraints}

$$
\begin{gathered}
a_{j}+w_{j}(\omega) \geq \\
a_{i}+w_{i}(\omega)+s_{i}(\omega)-M\left(2-x_{i n}-x_{j n}\right) \\
\forall j \in S, i \in S P_{j}, n \in N
\end{gathered}
$$

$$
\begin{gathered}
a_{j}+w_{j}(\omega) \geq \\
a_{i}+w_{i}(\omega)+s_{i}(\omega)+t_{i}(\omega)-M\left(2-y_{i c}-y_{j c}\right) \\
\forall j \in S, i \in S P_{j}, c \in C \\
o_{n}(\omega) \geq a_{i}+w_{i}(\omega)+s_{i}(\omega)+t_{i}(\omega)-H-M\left(1-x_{i n}\right) \\
\forall i \in S, n \in N \\
o_{n}(\omega) \leq L \quad \forall n \in N \\
w_{i}(\omega), o_{n}(\omega) \geq 0 \quad \forall i \in S, n \in N
\end{gathered}
$$

The objective function (1) minimizes the expected weighted sum of patient waiting time and nurse overtime. Note that there is no penalty associated with the first stage in the objective function. It only minimizes the expected value of the secondstage recourse function which is shown in equation (7).

Constraint (2) ensures that each patient is assigned to exactly one nurse. Constraint (3) enforces that each patient is assigned to exactly one chair. Constraint (4) restricts the number of patients assigned from each patient class to a nurse. Note that the upper limit, $P_{k}$, is calculated as shown in the equation below.

$$
\mathrm{P}_{\mathrm{k}}=\left\lceil\frac{|\mathrm{N}|}{\left|\mathrm{S}_{\mathrm{k}}\right|}\right\rceil \quad \forall \mathrm{k} \in \mathrm{K}
$$

Equation (13) sets $P_{k}$ by dividing the number of nurses by the number of patients in class $k$, and rounding up if the resulting value is fractional. Note that constraints (5) and (6) represent the binary and non-negativity restrictions on the first-stage variables, respectively.

At the second stage, constraints (8)-(12) are formulated for each scenario. Constraint (8) ensures that the treatment of a patient starts after the pre-medication is completed for the preceding patient assigned to the same nurse. Constraint (9) represents that the treatment of a patient can start after the treatment is completed for the preceding patient assigned to the same chair. Constraint (10) calculates the overtime incurred for each nurse. Constraint (11) places a limit on nurse overtime. This is to ensure that the workload for a nurse does not become excessive in any case. Constraint (12) defines the non-negativity restrictions on the second-stage variables.

\subsection{Model enhancement}

We formulate a valid inequality to improve the computational performance by utilizing the special structure of the model. In particular, we test the impact of a symmetry-breaking constraint into the computational time.

We formulate a symmetry-breaking constraint that is valid only for the set that includes the first $|C|$ patients in the appointment list. As the chairs are identical, it does not matter where a patient is assigned to in case there are multiple chairs available for initiating the patient treatment. Therefore, the following constraint which enforces the assignment of the patient i to chair $c=i$ is valid:

$$
y_{i c}=1 \quad \forall i \in S, c \in C: i=c
$$

\section{Experimental study}

We used data from the Outpatient Chemotherapy Unit at Hacettepe Oncology Hospital in our numerical experiments. The data was collected through the period from November 
2017 to March 2018. The data set includes planned treatment times and actual pre-medication and infusion times for patients. The treatment time for a patient is equal to the summation of pre-medication and infusion times for the patient. The descriptive statistics related to our data set that summarizes the actual pre-medication and infusion times is given in Table 1.

Table 1. Descriptive statistics summarizing actual premedication and infusion time (in minutes).

\begin{tabular}{ccc}
\hline & $\begin{array}{c}\text { Pre-medication } \\
\text { time }\end{array}$ & Infusion time \\
\hline Average & 15.3 & 112.5 \\
Minimum & 0 & 16 \\
Maximum & 36 & 217 \\
95\% CI & {$[14.61,16.09]$} & {$[104.56,120.35]$} \\
\hline
\end{tabular}

The confidence intervals (CI) provided in the table illustrates the variability in the treatment durations. Figure 1 shows the variability in treatment durations for the appointments planned for 150 minutes. The figure provides the percentage frequency of treatment durations actually observed for the patients for whom 150 minutes of slots were reserved. The scope of the variability signifies the need for considering uncertainty while modelling chemotherapy scheduling decisions.

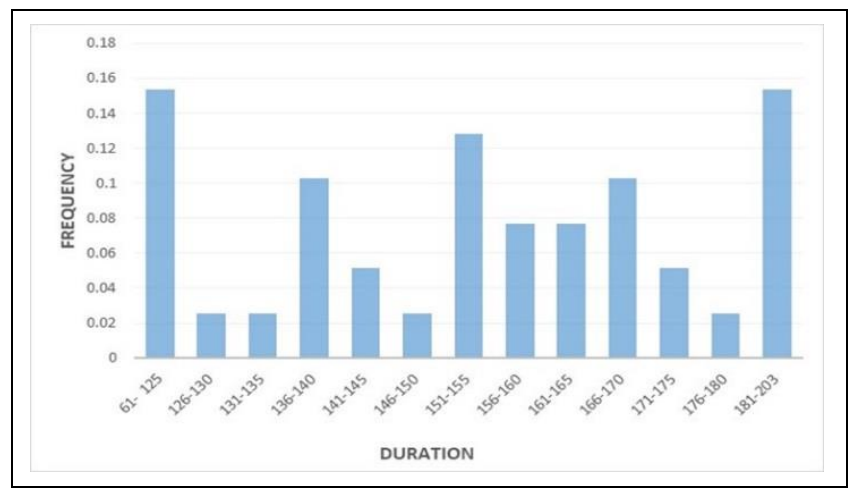

Figure 1. Percentage frequency of actual duration values (in minutes) for treatments planned for $150 \mathrm{~min}$.

The patients in the data set are grouped into four patient classes according to the planned treatment time values. The planned treatment time intervals considered to create patient classes are as follows: $[20,45]$ for class $1,(45,100]$ for class $2,(100$, $150]$ for class 3 , and $(150,240]$ for class $4.26 .96 \%$ of the patients in the data set falls into the first class, $7.84 \%$ into the second, $33.34 \%$ into the third, while $31.86 \%$ falls into the fourth class according to their planned treatment time values. We also present the actual pre-medication and infusion times observed for the patients in each class on Table 2.

Table 2. Intervals of the actual pre-medication and infusion times (in minutes) associated with each patient class.

\begin{tabular}{ccc}
\hline Patient class & Pre-medication time & Infusion time \\
\hline 1 & {$[0,14]$} & {$[16,44]$} \\
2 & {$[6,35]$} & {$[29,80]$} \\
3 & {$[8,26]$} & {$[74,132]$} \\
4 & {$[6,27]$} & {$[125,217]$} \\
\hline
\end{tabular}

The following summarizes the approach we used to sample premedication and infusion times for our model parameters: We first generated a random number between 0 and 1 . The value is used to determine the class of a patient by considering the relative frequencies of the classes. Then, the pre-medication and infusion times for the patient are set by randomly selecting from the actual values for the patients in the associated class. The model was solved through Microsoft Visual C++ using CPLEX 12.9 Concert Technology. The experiments were conducted on a server with dual Intel Xeon Silver 411410 core processors running at $2.4 \mathrm{GHz}$ and $128 \mathrm{~GB}$ of memory under OpenSuse Linux.

We performed each experiment on an instance set that consists of 10 instances created randomly. The number of scenarios in each instance is set to 100 . For each instance, we solved the 2SMIP model by formulating the second-stage constraints for all 100 scenarios. The objective function (1) value is provided by the solver, which evaluates the expected value function based on those 100 scenarios. 12 patients are scheduled in all of the instances. Furthermore, the clinic is open for 8 hours. The number of chairs and nurses, and the weights for waiting time and overtime are varied over different experiments.

\subsection{Impact of adding the symmetry-breaking constraint}

We first measure the amount of computational time saved by adding the symmetry-breaking constraint. In these experiments, we set the number of chairs and nurses as 3 and 2 , respectively. We set the value of $\lambda$ as 0.3 , as the overtime per minute is given higher priority over the waiting time per minute in the chemotherapy unit we studied.

We first solve the model (1)-(12) by CPLEX using ten instances, and report the run time for each of them. We then add constraint (14) to the model and solve the resulting model by CPLEX using the same instances. As the results in Table 3 show, adding the symmetry breaking constraint improves the computational time by $48.18 \%$ on average. The constraint reduced the solution time significantly in nine out of ten instances. Therefore, we add constraint (14) to the model, and use the resulting model in the rest of the experiments.

Table 3. Impact of the symmetry-breaking constraint into the computational time (in seconds).

\begin{tabular}{ccc}
\hline Instance No & Without Constraint & With Constraint \\
\hline 1 & 440.98 & 251.15 \\
2 & 424.73 & 285.84 \\
3 & 424.74 & 291.89 \\
4 & 470.94 & 286.24 \\
5 & 312.02 & 490.61 \\
6 & 648.7 & 256.64 \\
7 & 334.42 & 127.35 \\
8 & 1040.56 & 216.82 \\
9 & 549.4 & 238.51 \\
10 & 328.23 & 132.65 \\
Average & 497.47 & 257.77 \\
\hline
\end{tabular}

\subsection{Characterization of the optimal solution}

Based on the first instance of the instance set referenced in the previous section, we present the optimal schedule (i.e. firststage solution of the 2SMIP) as an example solution on Table 4. The table illustrates the class, optimal appointment time, assigned chair and nurse for each patient, respectively. The solution shows that the schedule is balanced in terms of the workload among two nurses thanks to the even allocation of patients of the same class. Note that the second-stage solution associated with the optimal schedule for this instance provided an average overtime value of 67.85 minutes, and average patient waiting time value of $4.14 \mathrm{~min}$. 
Table 4. An example optimal solution. $\mathrm{C}$ and $\mathrm{N}$ stand for chair and nurse, respectively, while App. Time represents appointment time in minutes.

\begin{tabular}{cccccccc}
\hline $\begin{array}{c}\text { Patient } \\
\text { Index }\end{array}$ & $\begin{array}{c}\text { Patient } \\
\text { Class }\end{array}$ & $\begin{array}{c}\text { App. } \\
\text { Time }\end{array}$ & C 1 & C 2 & C 3 & N 1 & N 2 \\
\hline 1 & 3 & 0 & & & x & & x \\
2 & 2 & 0 & & x & & x & \\
3 & 4 & 17 & $\mathrm{x}$ & & & & $\mathrm{x}$ \\
4 & 3 & 92 & & $\mathrm{x}$ & & & $\mathrm{x}$ \\
5 & 4 & 218 & $\mathrm{x}$ & & & $\mathrm{x}$ & \\
6 & 4 & 153 & & & $\mathrm{x}$ & & $\mathrm{x}$ \\
7 & 2 & 249 & & $\mathrm{x}$ & & & $\mathrm{x}$ \\
8 & 1 & 346 & & & $\mathrm{x}$ & & $\mathrm{x}$ \\
9 & 3 & 360 & & $\mathrm{x}$ & & $\mathrm{x}$ & \\
10 & 3 & 404 & & & $\mathrm{x}$ & $\mathrm{x}$ & \\
11 & 4 & 422 & $\mathrm{x}$ & & & $\mathrm{x}$ & \\
12 & 1 & 529 & & $\mathrm{x}$ & & $\mathrm{x}$ & \\
\hline
\end{tabular}

4.3 Sensitivity to the weights of performance measures

We analyze the sensitivity of the optimal solution to the weights of performance measures by varying the values of $\lambda$. We start with 0 and increase the value by 0.1 at each experiment until it becomes 1 . We observe how the average waiting time per patient and average overtime per nurse changes due to the increases in $\lambda$. The number of chairs and nurses in all experiments are again set to 3 and 2, respectively.

Table 5 shows that the average patient waiting time decreases while the average nurse overtime increases as $\lambda$ is incremented. The average waiting time drops sharp at the beginning, but the rate of change decreases as $\lambda$ becomes greater. On the other hand, the rate of increase in average overtime gets larger with greater values of $\lambda$.

Table 5 . Sensitivity of the average patient waiting time and nurse overtime (both in minutes) to $\lambda$ values.

\begin{tabular}{ccc}
\hline$\lambda$ & Patient Waiting Time & Nurse Overtime \\
\hline 0 & 56.01 & 52.81 \\
0.1 & 10.11 & 56.64 \\
0.2 & 6.43 & 60.42 \\
0.3 & 4.36 & 64.47 \\
0.4 & 3.11 & 68.51 \\
0.5 & 2.12 & 73.38 \\
0.6 & 1.48 & 78.09 \\
0.7 & 0.98 & 83.67 \\
0.8 & 0.51 & 92.32 \\
0.9 & 0.24 & 101.72 \\
1 & 0.05 & 300 \\
\hline
\end{tabular}

When $\lambda$ is equal to 0 , the model considers only the nurse overtime in the objective function. Therefore, all patients may be asked to arrive at the beginning of the day to ensure that the nurses and chairs would be utilized to the greatest extent. This is why the average patient waiting time for this case is quite large. On the other hand, the model minimizes only the average patient waiting time in case $\lambda$ is set to 1 . For this purpose, the nurse overtime is set to the maximum possible value that it can take. Since we allow maximum of five hours in the model, the overtime is found as 300 minutes in all scenarios, which is not realistic in practice. However, even when we slightly give importance to nurse overtime by setting $\lambda$ as 0.9 , the average overtime becomes 102 minutes. Note that the extreme cases where $\lambda$ is 0 or 1 are not realistic weights for the outpatient chemotherapy units. However, we test them to see the boundary values of performance measures. The values in Table 5 are also plotted in Figure 2 to better illustrate the tradeoff between average patient waiting time and nurse overtime.

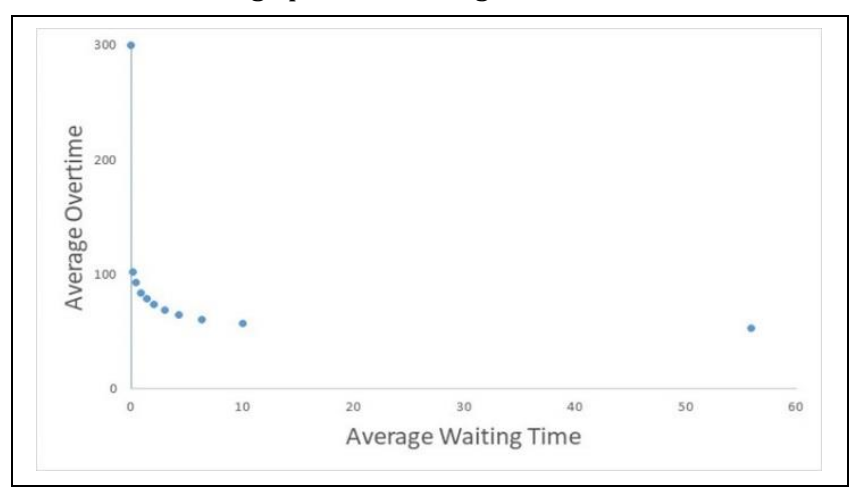

Figure 2. Trade-off between average nurse overtime and patient waiting time (both in minutes) due to changes in $\lambda$

The $\lambda$ value of 0.3 better represents the perspectives of the outpatient chemotherapy unit managers. The average patient waiting time is less than five minutes, while the average nurse overtime turns out to be at manageable levels in this case. Therefore, we consider 0.3 as the baseline value for $\lambda$.

\subsection{Impact of the numbers of chairs and nurses}

We examine the impact of varying the number of chairs and nurses into the performance measures. The tested values of $|C|$ ranges between 1 and 4 . While designing the experiments, we ensured that the number of nurses never exceeds the number of chairs. Therefore, the values of $|N|$ range between 1 and $|C|$. We provide the average waiting time and nurse overtime values for different combinations of $|C|$ and $|N|$ in Tables 6 and 7, respectively. Note that the contents of Tables 6 and 7 are also represented by Figures 3 and 4, respectively. Note that we repeat our experiments for each value of $\lambda$, changing between 0.1 and 0.9 . Table 6 illustrates that the average waiting time decreases as the number of chairs increases while the number of nurses is kept constant for any value of $\lambda$, as expected. However, this improvement cannot be always observed when the number of nurses increases while the number of chairs stays constant. This may seem unexpected, but it occurs due to constraint (4), which balances nurse workloads. As $P_{k}$ in constraint (4) is set according to the formula shown in equation (13), an increase in the number of nurses decreases the number of patients that each nurse can take care of. Therefore, this does not guarantee a decrease in patient waiting time.

Table 7 shows that the average nurse overtime decreases significantly when the number of chairs increases as the number of nurses stays constant for any value of $\lambda$. A significant improvement in average nurse overtime is observed also when the number of nurses is increased while the number of chairs is kept at the same value. The results in Tables 6 and 7 help us identify appropriate values for the number of chairs and nurses. The average nurse overtime may exceed one hour when $|C| \leq$ 3 for any value of $|N|$ depending on the preferred value of $\lambda$. Therefore $|C|=4$ may be a better choice to obtain reasonable nurse overtime values. The average nurse overtime drops below one hour when $|N| \leq 2$ for the case $|C|=4$. The average overtime value does not even exceed 30 minutes when $|N|=2$ in that case. Furthermore, the combination of $|N|=2$ and $|C|=$ 4 results in less than 4 minutes of patient waiting time. Therefore, we suggest using two nurses for four chairs in a chemotherapy unit. 


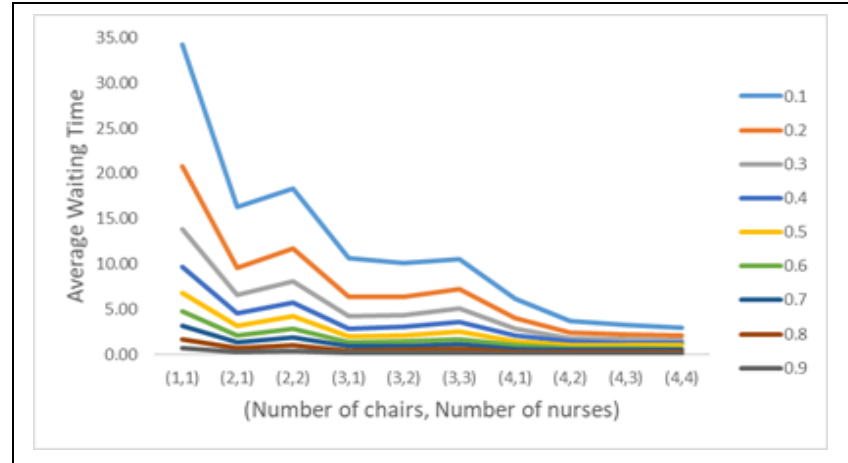

Figure 3. Change in average waiting time (in minutes) depending on the number of chairs and nurses for each value of $\lambda$.

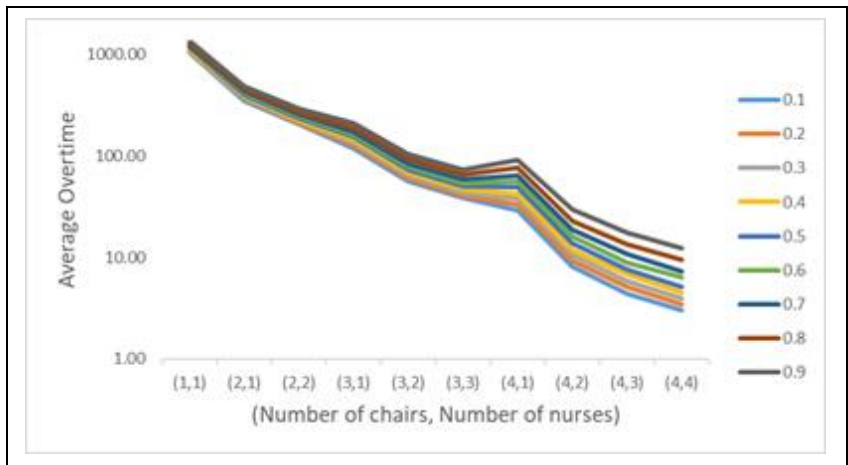

Figure 4. Change in average overtime (in minutes in logarithmic scale) depending on the number of chairs and nurses for each value of $\lambda$.

Table 6. Impact of the numbers of chairs and nurses on average patient waiting time (in minutes) for different values of $\lambda$.

\begin{tabular}{cccccccccc}
\hline \multicolumn{10}{c}{$\lambda$} \\
\hline$(|\mathrm{C}|,|\mathrm{N}|)$ & 0.1 & 0.2 & 0.3 & 0.4 & 0.5 & 0.6 & 0.7 & 0.8 \\
$(1,1)$ & 34.23 & 20.75 & 13.81 & 9.71 & 6.77 & 4.77 & 3.19 & 1.74 & 0.9 \\
$(2,1)$ & 16.29 & 9.54 & 6.57 & 4.58 & 3.14 & 2.17 & 1.41 & 0.72 & 0.27 \\
$(2,2)$ & 18.28 & 11.74 & 8.13 & 5.77 & 4.24 & 2.92 & 1.91 & 1.06 & 0.39 \\
$(3,1)$ & 10.69 & 6.37 & 4.26 & 2.92 & 2.03 & 1.41 & 0.93 & 0.46 & 0.20 \\
$(3,2)$ & 10.11 & 6.43 & 4.36 & 3.09 & 2.12 & 1.48 & 0.98 & 0.50 & 0.21 \\
$(3,3)$ & 10.56 & 7.20 & 5.14 & 3.56 & 2.58 & 1.73 & 1.15 & 0.59 & 0.24 \\
$(4,1)$ & 6.19 & 4.02 & 2.85 & 2.13 & 1.52 & 1.05 & 0.67 & 0.35 & 0.15 \\
$(4,2)$ & 3.72 & 2.49 & 1.85 & 1.46 & 1.06 & 0.78 & 0.53 & 0.29 & 0.11 \\
$(4,3)$ & 3.32 & 2.25 & 1.69 & 1.28 & 1.01 & 0.75 & 0.51 & 0.29 & 0.11 \\
$(4,4)$ & 2.93 & 2.07 & 1.56 & 1.26 & 1.01 & 0.67 & 0.49 & 0.27 & 0.11 \\
\hline
\end{tabular}

Table 7. Impact of the numbers of chairs and nurses on average nurse overtime (in minutes) for different values of $\lambda$.

\begin{tabular}{|c|c|c|c|c|c|c|c|c|c|}
\hline & \multicolumn{9}{|c|}{$\lambda$} \\
\hline$(|\mathrm{C}|,|\mathrm{N}|)$ & 0.1 & 0.2 & 0.3 & 0.4 & 0.5 & 0.6 & 0.7 & 0.8 & 0.9 \\
\hline$(1,1)$ & 1041.08 & 1068.85 & 1095.85 & 1122.35 & 1151.30 & 1180.67 & 1216.33 & 1270.15 & 1344.52 \\
\hline$(2,1)$ & 348.25 & 362.02 & 373.64 & 386.25 & 400.23 & 414.50 & 431.40 & 456.22 & 488.04 \\
\hline$(2,2)$ & 203.71 & 210.48 & 217.64 & 225.20 & 232.79 & 242.57 & 253.70 & 268.92 & 292.17 \\
\hline$(3,1)$ & 118.03 & 126.96 & 135.21 & 143.82 & 152.66 & 161.81 & 172.44 & 189.56 & 207.67 \\
\hline$(3,2)$ & 56.63 & 60.42 & 64.46 & 68.55 & 73.36 & 78.08 & 83.67 & 92.39 & 102.84 \\
\hline$(3,3)$ & 38.39 & 40.70 & 43.45 & 46.84 & 50.03 & 54.17 & 58.55 & 65.22 & 73.47 \\
\hline$(4,1)$ & 29.07 & 33.42 & 38.02 & 42.64 & 48.66 & 55.52 & 64.21 & 75.60 & 90.05 \\
\hline$(4,2)$ & 8.05 & 9.31 & 10.61 & 11.86 & 13.86 & 15.93 & 18.75 & 22.99 & 29.63 \\
\hline$(4,3)$ & 4.41 & 5.13 & 5.89 & 6.79 & 7.65 & 8.90 & 10.76 & 13.38 & 17.57 \\
\hline$(4,4)$ & 3.03 & 3.46 & 3.97 & 4.47 & 5.08 & 6.32 & 7.35 & 9.38 & 12.31 \\
\hline
\end{tabular}

\subsection{Value of stochastic solution}

We assess the value of stochastic solution (VSS) by comparing the objective function (1) values calculated for each of the 2SMIP model solution and mean value problem solution. The VSS value serves as the indicator of the benefit of considering uncertainty while scheduling chemotherapy appointments. The mean value problem is a variant of our problem, where the random parameters representing pre-medication and infusion durations are replaced by their expected values. Let $z^{S M I P}$ represent the optimal objective value of our 2SMIP model solution, and $z^{M V}$ be the optimal objective function (1) value calculated by fixing the values of the first-stage decision variables based on the mean value problem solution, then VSS= $z^{M V}-z^{S M I P}$.

In Table 8, we report the relative VSS, which is the VSS given as a percentage of $z^{M V}$. The relative VSS is calculated for each value of $\lambda$ in the table. The average of relative VSS values is found as $86 \%$, which indicates a great benefit for considering uncertainty in the model. Note that the VSS values are even more than $90 \%$ for large values of $\lambda$.

Table 8. Relative VSS for different values of $\lambda$

\begin{tabular}{cccc}
\hline$\lambda$ & $\mathrm{z}^{\text {SMIP }}$ & $\mathrm{z}^{\mathrm{MV}}$ & Relative VSS\% \\
\hline 0 & 105.62 & 296.64 & 64.39 \\
0.1 & 114.11 & 442.76 & 74.23 \\
0.2 & 112.11 & 467.38 & 76.01 \\
0.3 & 105.95 & 531.26 & 80.06 \\
0.4 & 97.11 & 720.43 & 86.52 \\
0.5 & 86.11 & 814.62 & 89.43 \\
0.6 & 73.09 & 930.82 & 92.15 \\
0.7 & 58.43 & 808.41 & 92.77 \\
0.8 & 41.76 & 1048.68 & 96.02 \\
0.9 & 22.92 & 857.52 & 97.33 \\
1 & 0.52 & 287.34 & 99.82 \\
\hline
\end{tabular}




\section{Conclusion}

In this article, we develop a two-stage stochastic mixed-integer programming model for setting patient appointment times for outpatient chemotherapy patients, and assigning patients to nurses and chairs while balancing the nurse workloads. The uncertainty exists due to both pre-medication and infusion durations. The trade-off between patient waiting time and nurse overtime is considered in the objective function. To the best of our knowledge, this is the first stochastic chemotherapy appointment scheduling study that proposes a model considering the nurse workload balance.

The stochastic mixed-integer programming model includes integer variables in the first stage and continuous variables in the second stage. Leaving only continuous variables in the second stage makes the realistic model instances solvable in a reasonable amount of time. The model was solved by CPLEX based on data collected from the Hacettepe Outpatient Chemotherapy Clinic. By incorporating symmetry-breaking constraints into the model, we further improved the computational performance of the solver.

We investigated the trade-off between two conflicting performance measures: patient waiting time and nurse overtime. Using our model, the manager can examine the tradeoff by only changing the weight of waiting time. We found that when the ratio of the weight for waiting time to the ratio of nurse overtime is $3: 7$, reasonable schedules would be obtained for the clinic manager. We also examined the impact of the number of chairs and nurses into the performances measures. We showed that when the number of chairs increases, the average overtime and waiting time also decreases. The overtime can also be improved by increasing the number of nurses. However, when the number of nurses increases, the average patient waiting time may not decrease because of the nurse workload balance constraint. This finding shows the importance of explicit consideration of this constraint. Note that we suggest $1: 2$ as the nurse-to-chair ratio for the managers to provide service with high-level of patient satisfaction and reasonable amount of nurse overtime. Finally, we also illustrated that the solutions obtained by considering uncertainty in pre-medication and infusion durations improve the objective value significantly with respect to the case where the uncertainty in parameters is ignored.

We plan to extend our model by including patient sequencing decisions in a future study. The resulting model may not be solved directly by a commercial solver in such a case. We intend to develop a sophisticated scenario-wise or stage-wise decomposition algorithm to solve the resulting formulation.

\section{Author contribution statements}

Serhat GUL, contributed to the article in all phases of the study including defining, modeling and solving the problem, performing literature review, conducting computational experiments, analyzing the results, and writing the manuscript. The input data was collected for Demir et al. [17], before this study started. It was collected by Serhat GUL's master's thesis student, Nur Banu DEMIR, during her study at Middle East Technical University.

\section{Ethics committee approval and conflict of interest statement}

There is no need to obtain permission from the ethics committee for the article prepared. There is no conflict of interest with any person / institution in the article prepared

\section{References}

[1] Wilson BE, Jacob S, Yap ML, Ferlay J, Bray F. "Estimates of global chemotherapy demands and corresponding physician workforce requirements for 2018 and 2040: a population-based study". The Lancet Oncology, 20(6), 769-780, 2019.

[2] Castaing J, Cohn A, Denton BT, Weizer A. "A stochastic programming approach to reduce patient wait times and overtime in an outpatient infusion center". IIE Transactions on Healthcare Systems Engineering, 6(3), 111-125, 2016.

[3] Lame G, Jouini O, Cardinal JSL. "Outpatient chemotherapy planning: A literature review with insights from a case study". IIE Transactions on Healthcare Systems Engineering, 6(3), 127-139, 2016.

[4] Gupta D, Denton B. "Appointment scheduling in health care: Challenges and opportunities". IIE Transactions, 40(9), 800-819, 2008.

[5] Cayirli T, Veral E. "Outpatient scheduling in health care: a review of literature". Production and Operations Management, 12(4), 519-549, 2003.

[6] Ahmadi-Javid A, Jalali Z, Klassen KJ. "Outpatient appointment systems in healthcare: a review of optimization studies". European Journal of Operational Research, 258(1), 3-34, 2017.

[7] Turkcan A, Zeng B, Lawley M. "Chemotherapy operations planning and scheduling". IIE Transactions on Healthcare Systems Engineering, 2(1), 31-49, 2012.

[8] Heshmat M, Nakata K, Eltawil A. "Solving the patient appointment scheduling problem in outpatient chemotherapy clinics using clustering and mathematical programming". Computers \& Industrial Engineering, 124, 347-358, 2018

[9] Sevinc S, Sanli UA, Goker E. "Algorithms for scheduling of chemotherapy plans". Computers in Biology and Medicine, 43(12), 2103-2109, 2013.

[10] Hesaraki AF, Dellaert NP, de Kok T. "Generating outpatient chemotherapy appointment templates with balanced flowtime and makespan". European Journal of Operational Research, 275(1), 304-318, 2019.

[11] Liang B, Turkcan A. "Acuity-based nurse assignment and patient scheduling in oncology clinics". Health Care Management Science, 19(3), 207-226, 2016.

[12] Santibanez P, Aristizabal R, Puterman ML, Chow VS, Huang W, Kollmannsberger C, Nordin T, Runzer N, Tyldesley S. "Operations research methods improve chemotherapy patient appointment scheduling". The Joint Commission Journal on Quality and Patient Safety, 38(12), 541-553, 2012.

[13] Hahn-Goldberg S, Beck JC, Carter MW, Trudeau M, Sousa P, Beattie K. "Solving the chemotherapy outpatient scheduling problem with constraint programming". Journal of Applied Operational Research, 6(3), 135-144, 2014. 
[14] Huggins A, Claudio D, Perez E. "Improving resource utilization in a cancer clinic: an optimization model". IIE Annual Conference and Expo 2014, Montreal, Canada, 31 May-3 June 2014.

[15] Alvarado M, Ntaimo L. "Chemotherapy appointment scheduling under uncertainty using mean-risk stochastic integer programming". Health Care Management Science, 21(1), 87-104, 2018.
[16] Mandelbaum A, Momcilovic P, Trichakis N, Kadish S, Leib $\mathrm{R}$, Bunnell CA. "Data-driven appointment scheduling under uncertainty: The case of an infusion unit in a cancer center". Management Science, 66(1), 1-28, 2019.

[17] Demir NB, Gul S, Çelik M. "A stochastic programming approach for chemotherapy appointment scheduling". Naval Research Logistics, 68(1), 112-133, 2021. 